\title{
Judith Butler y Beatriz Preciado: una comparación de dos modelos teóricos de la construcción de la identidad de género en la teoría queer ${ }^{1}$
}

\author{
Judith Butler and Beatriz Preciado: a comparison of two \\ theoretical models of the construction of gender identity in \\ Queer theory
}

Recibido: 06 de marzo de 2015 - Revisado: 23 de septiembre de 2015 - Aceptado: 05 de octubre de 2015

\begin{abstract}
Alexis Emanuel Gros ${ }^{2}$
\section{Resumen}

El presente trabajo se propone contrastar dos modelos teóricos de la construcción de la identidad de género dentro de la teoría queer: el modelo performativo-teatral de Judith Butler y el biodrag de Beatriz Preciado. Para cumplir con este objetivo, se procede en dos pasos. Primero, se analiza la crítica de Butler a la metafísica de género y se presentan los lineamientos centrales de su modelo performativo-teatral. Segundo, se estudia el rol que los conceptos de farmacopornocapitalismo y posmoneyismo desempeñan en la obra de Preciado, para luego pasarse a un análisis de su modelo biodrag.
\end{abstract}

\section{Palabras clave}

Teoría queer, fenomenología, identidad de género, construcción, performatividad, feminismo, farmacopornocapitalismo, posmoneyismo.

\begin{abstract}
This paper aims to contrast two theoretical models of the construction of gender identity within queer theory: the performative-stage model of Judith Butler and Beatriz Preciado's biodrag. To meet our goal, we proceed in two steps. First, Butler's criticism of gender metaphysics is analyzed and the central guidelines of her performative-stage model are presented. Second, the role that the concepts of pharmaco-porno-capitalism and post-Money-ism play in the work of Preciado is studied, coming then to an analysis of her biodrag model.
\end{abstract}

\section{Keywords}

Queer theory, phenomenology, gender identity, construction, performativity, feminism, pharmaco-porno-capitalism, pos-Money-ism.

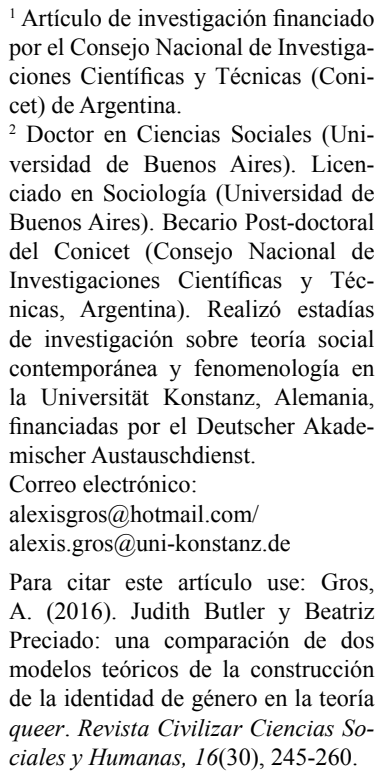

${ }^{1}$ Artículo de investigación financiado por el Consejo Nacional de Investigaciones Científicas y Técnicas (Conicet) de Argentina.

${ }^{2}$ Doctor en Ciencias Sociales (Universidad de Buenos Aires). Licenciado en Sociología (Universidad de Buenos Aires). Becario Post-doctoral del Conicet (Consejo Nacional de Investigaciones Científicas y Técnicas, Argentina). Realizó estadías de investigación sobre teoría social contemporánea y fenomenología en la Universität Konstanz, Alemania, financiadas por el Deutscher Akademischer Austauschdienst.

Correo electrónico:

alexisgros@hotmail.com/ alexis.gros@uni-konstanz.de

Para citar este artículo use: Gros, A. (2016). Judith Butler y Beatriz Preciado: una comparación de dos modelos teóricos de la construcción de la identidad de género en la teoría queer. Revista Civilizar Ciencias Sociales y Humanas, 16(30), 245-260. 


\section{Introducción $^{1}$}

A comienzos de los años noventa, aparece en los Estados Unidos una perspectiva novedosa en el campo de los estudios de género: la teoría queer. Esta posición, representada por autoras como Judith Butler, Eve Kosofski Sedgwick y Teresa de Lauretis, entre otras, pone en cuestión el carácter "natural" $-\mathrm{y}$, por tanto, ineludible - de la llamada heteronormatividad: la matriz binaria según la cual se asignan, clasifican y regulan las identidades de género en las sociedades occidentales. Para la teoría queer, lejos de estar inscrita en la complexión ontológica del mundo o fijada en la constitución biológica de los seres humanos, esta matriz es una construcción sociohistórica. En la tarea de descentrar y desmontar el régimen sexual dominante en Occidente, los teóricos queer recurren a procedimientos críticos que se inspiran en la deconstrucción posestructuralista de la metafísica occidental.

La desestabilización queer del régimen heterosexualista no obedece a fines meramente cognoscitivos. Por el contrario, está guiada por un claro objetivo ético-político: volver posible la vida de las "sexualidades periféricas"; es decir, de las sexualidades que, al no ajustarse a los parámetros dominantes en Occidente, se ven condenadas al "rechazo social, la discriminación y el estigma" (Fonseca-Hernández \& QuinteroSoto, 2009, p. 44). Por esta razón, para comprender a cabalidad el cariz de la teoría queer, es preciso dar cuenta de su vinculación íntima con el movimiento político queer, que surge a mediados de los años ochenta.

Como es sabido, en su acepción común, la voz inglesa queer es un insulto que refiere de manera peyorativa a todas las formas "anómalas" de la sexualidad -"puto", "maricón", "gay", etc.- (Fonseca-Hernández \& Quintero-Soto, 2009; Preciado, 2012). En el contexto de la crisis del VIH, un conjunto de microgrupos radicales -Act Up, Radical Furies y Lesbian Avengers, entre otros-se reapropia de esta injuria y cambia radicalmente su sentido. En manos de este nuevo movimiento, la palabra queer deviene motivo de orgullo. Se convierte en un signo de resistencia a procesos de normalización y exclusión sexual que tienen lugar no solo en la sociedad heterosexista, sino también dentro de aquellos espacios políticos que se sitúan críticamente ante la misma: el feminismo y el movimiento homosexual (Preciado, 2012). Para el movimiento queer, al interior de estas posiciones pretendidamente progresistas y emancipatorias, pueden reconocerse tendencias excluyentes y normalizadoras análogas a las del heterosexualismo.

A menudo, los sectores que dominan al interior de estos amplios espacios políticos hacen pasar su identidad particular por la identidad general del movimiento: así, por ejemplo, en el feminismo, suele identificarse la figura de la "mujer" con la mujer blanca y occidental. Esto da lugar a procesos de paternalismo, vampirismo y ventrilocuismo que condenan a los grupos subordinados -las bolleras, los/ las transexuales, los/las inmigrantes, los/las mestizos/as, etc.- a situaciones de ostracismo (Leciña-Blanchard, 2006).

Combatiendo los peligros de toda esencialización identitaria, el movimiento queer se define como "posidentitario" (Preciado, 2012). "No es una identidad más en el folklore multicultural, sino una posición crítica atenta a los procesos de exclusión y de marginalización que genera toda ficción identitaria" (párr. 5). En efecto, lejos de presentarse como un movimiento de "homosexuales" o de "mujeres", el queer quiere mostrarse como un movimiento político de “disidentes de género" (párr. 5).

De lo antedicho se desprende que una de las misiones teóricas fundamentales, si no la fundamental, de la teoría queer consiste en la desontologización de las identidades de género, desontologización que solo puede lograrse a través de la puesta de manifiesto del carácter construido y contingente de las mismas. En este 
sentido, el constructivismo se muestra como el antídoto par excellence para el esencialismo y sus consecuencias violentas. En efecto, dejando de lado los innegables matices, puede afirmarse que prácticamente todos los teóricos queer coinciden en que el género es un constructo sociohistórico (c.f. Butler, 1990/2007; De Lauretis, 1987; Sedwick, 1990; Preciado, 2008, entre otras).

Ahora bien, y aquí radica el punto de partida de este artículo, en la actualidad no existe acuerdo absoluto sobre el modo en que tiene lugar esta construcción. Durante toda la década del noventa, el modelo teatralperformativo desarrollado por Judith Butler ha sido la perspectiva dominante a este respecto (Preciado, 2010). Sin embargo, en los últimos años, han aparecido posiciones alternativas como el modelo biodrag de Beatriz Preciado (2008, 2009), que desafían la hegemonía de esta concepción.

El presente trabajo se propone contrastar el modelo teórico butleriano de la construcción de la identidad de género con la novedosa posición desarrollada por Preciado. Para cumplir con este objetivo, el escrito se escinde en dos apartados. En el primero de ellos después de pasarse revista a la crítica butleriana de la metafísica de género, se lleva a cabo una presentación de los lineamientos centrales del modelo performativo-teatral. En el segundo se presentan los conceptos preciadianos de farmacopornocapitalismo y posmoneyismo $\mathrm{y}$, luego, se bosquejan los lineamientos fundamentales del modelo biodrag.

Antes de comenzar con la exposición, es preciso realizar una serie de aclaraciones referidas al alcance y límites de este documento. En primer término, debe señalarse que el mismo no pretende, de ninguna manera, ser una presentación exhaustiva de las obras completas de Butler y Preciado. Antes bien, se opta por analizar de forma rigurosa cuatro textos de las autoras que resultan de cardinal importancia para el problema que aquí se plantea, a saber: Gender trouble y Performative acts and gender constitution: an essay in phenomenology and feminist theory, de Butler; y Testo yonqui y $L a$ invención del género, o el tecnocordero que devora a los lobos, de Preciado. La elección de estos dos escritos butlerianos tempranos -de 1988 y 1990, respectivamente- obedece a que Preciado (2009, pp. 26-28) dirige sus objeciones fundamentales a la primera Butler -esto es, a la Butler del modelo performativo-teatral-, y no a la de Bodies that matter ${ }^{2}$.

En lo que refiere a Preciado, se analizará Testo yonqui-de 2008-debido a su proximidad temporal y conceptual con La invención del género, o el tecnocordero que devora a los lobos-de 2009-. Este último artículo, en el que la autora española esboza de manera preliminar una comparación entre su modelo teórico y el butleriano, actuó como puntapié inicial de las reflexiones que animan este escrito.

\section{Judith Butler: la crítica a la metafísica de género y el modelo de la performatividad teatral}

\section{La crítica a la metafísica de género.}

Inspirada en las obras de Adrienne Rich y Michel Foucault, Butler sostiene que en la modernidad occidental, se ha construido e instituido un régimen normativo en lo concerniente al género y la sexualidad: la heteronormatividad o heterosexualidad obligatoria (Butler, 1990/2007, p. 8; Femenías, 2002). Este régimen define cuáles son las identidades de género inteligibles y correctas, y castiga aquellas que no lo son. Según los cánones de la heteronormatividad, solo existen dos identidades sexuales verdaderas, a saber: "hombre" y "mujer".

Se trata de dos modelos morfológicos ideales en los que se constata una coherencia perfecta entre sexo biológico, género y deseo. "Los géneros 'inteligibles' son los que de alguna manera instauran y mantienen relaciones de 
coherencia y continuidad entre sexo, género, práctica sexual y deseo" (Butler, 1990/2007, p. 73). Así, por ejemplo, para ser considerado como "hombre" dentro de los patrones de esta matriz cultural, un individuo debe contar con órganos genitales definidos como masculinos, seguir prácticas de género adscriptas normalmente a la masculinidad y orientar su deseo a sujetos del sexo femenino.

En caso de no existir una concordancia perfecta entre estos tres aspectos de la sexualidad, el sujeto en cuestión es estigmatizado como anormal y sometido a rigurosas consecuencias punitivas. Efectivamente, para Butler, la matriz cultural heterosexualista "exige que algunos tipos de 'identidades' no puedan 'existir': aquellas en las que el género no es consecuencia del sexo y otras en las que las prácticas del deseo no son 'consecuencia' ni del sexo ni del género" (Butler, 1990/2007, p. 73). Estas identidades falsas o ininteligibles son víctima de una severa violencia excluyente que las condena a una suerte de "suspensión de la vida, o [a] una sentencia de muerte sostenida" (p. 24).

Desde la perspectivade Butler(1990/2007), el régimen heterosexista ha sido naturalizado en el sentido común de Occidente, es decir, se ha convertido en un estado de cosas obvio que parece estar inscrito en la estructura ontológica de la realidad. Para la autora, la naturalización de la heteronormatividad tiene como consecuencia la invisibilización de su carácter eminentemente violento y de su condición de constructo contingente. En el momento de escribir Gender trouble, señala Butler (1990/2007),

[...] identificar esta violencia [la violencia normativa de género] era difícil porque el género era algo que se daba por sentado y que al mismo tiempo se vigilaba terminantemente. Se presuponía que era una expresión natural del sexo o una constante natural que ninguna acción humana era capaz de modificar (p. 24).

De acuerdo con Butler, la heterosexualidad obligatoria no es percibida por los sujetos cotidianos -ni por la mayoría de los académicos- como el violento dispositivo normativo que en realidad es, sino más bien como una descripción inocente de la naturaleza eterna de las cosas (Femenías, 2002). La heteronormatividad esconde su carácter prescriptivo y contingente en el halo aparentemente aséptico y eterno de nociones como las de naturaleza y esencia. Podría afirmarse que el propósito teórico primordial de la obra de Butler es la desnaturalización y desestabilización del esclerotizado régimen heterosexualista. Esta empresa filosófica no debe entenderse como un mero devaneo intelectual. Antes bien, según las palabras de la propia Butler, obedece, en última instancia, a un preciso objetivo de carácter ético-político: "contrarrestar la violencia de las normas de género" (Butler, 1990/2007, p. 29).

El empeño obstinado de este texto [Gender trouble] por "desnaturalizar" el género tiene su origen [en] el deseo intenso de contrarrestar la violencia normativa que conllevan las morfologías ideales del sexo, así como eliminar las suposiciones dominantes acerca de la heterosexualidad natural o presunta que se basan en los discursos ordinarios y académicos acerca de la heterosexualidad [...] obedece a un deseo de vivir, de hacer la vida posible, y de replantear lo posible en cuanto tal (p. 24).

Para llevar a cabo esta iniciativa, la pensadora norteamericana se sirve de herramientas teóricas de raigambre nietzscheana que retoma del posestructuralismo francés, a saber: la deconstrucción y la genealogía. La condición de posibilidad de la aplicación de este instrumental filosófico en un terreno foráneo como el de los estudios de género es, para Butler, la analogía estructural que existe entre el régimen heterosexualista y la "metafísica de la sustancia" occidental. Butler habla, en efecto, de una "metafísica de la sustancia de género" (Butler, 1990/2007, p. 79).

Como es sabido, en sus diferentes variantes la metafísica occidental cree poder aprehender racionalmente la "esencia del 
mundo", el "sentido y significado del todo", y expresarlo en un sistema teórico unitario (Horkheimer, 1933/1968, p. 39). Esta confianza se sustenta en la supuesta identidad del ser con el pensamiento: el mundo está organizado de manera racional, constituido del mismo material que la inteligencia humana y, en consecuencia, su estructura puede ser descubierta por todo hombre que haga uso sistemático de su capacidad de razonar. Desde el pensamiento griego clásico, la metafísica occidental ha concebido la estructura del ser como organizada en términos de sustancia y accidente. El mundo estaría compuesto de múltiples sustancias: entes indivisibles, idénticos a sí mismos y portadores de existencia independiente que actúan como sustrato fijo de atributos o accidentes (por ejemplo, el sistema monadológico de Leibniz, 1714/2004).

La metafisica de la sustancia es una frase relacionada con Nietzsche dentro de la crítica actual del discurso filosófico. En un comentario sobre Nietzsche, Michel Haar afirma que numerosas ontologías filosóficas se han quedado atrapadas en ciertas ilusiones de "Ser" y "Sustancia" animadas por la idea de que la formulación gramatical de sustancia y atributo refleja la realidad ontológica previa de sustancia y atributo (p. 77).

Teniendo esto en mente, resulta sencillo comprender el isomorfismo señalado por Butler entre metafísica y heteronormatividad. Puede hablarse de una metafísica de género operante en el sentido común occidental, en la medida que este cree poder aprehender la estructura ontológica de la realidad de género. La misma estaría estructurada desde el vamos y ad eternum en dos tipos de "sustancias constantes": los sujetos "masculinos" y los sujetos "femeninos", siendo cada tipo de sustancia portadora de una serie de accidentes que le corresponden (Leibniz, 1714/2004, p. 83). Para Butler, en la ontología sexual ínsita en el sentido común occidental, los accidentes de género -esto es, los actos particulares en los cuales el género se manifiesta: gestos, vestimenta, posturas, etc.- son concebidos como atributos que expresan una sustancia de género existente a priori. Desde esta perspectiva, un individuo nace dotado de una identidad de género inmutable definida por el sexo biológico, identidad que se pone de manifiesto a través de un conjunto de comportamientos acordes con ella.

La teoría popular implícita de los actos y los gestos como expresivos del género sugiere que el género mismo es algo previo a los varios actos, posturas y gestos mediante los cuales es dramatizado y conocido; de hecho, el género aparece para la imaginación popular como un núcleo sustancial que podría ser entendido como un correlato psíquico o espiritual del sexo biológico (Butler, 1988, p. 528).

Ahora bien, para comprender cabalmente la analogía encontrada por Butler entre metafísica de la sustancia y régimen heterosexualista, es preciso tener en cuenta otro rasgo fundamental del pensamiento metafísico de Occidente. Desde sus orígenes en la antigua Grecia, la metafísica jamás tuvo fines meramente cognoscitivos. Por el contrario, la obtención del saber absoluto sobre la constitución del ser estuvo siempre direccionada a fundamentar de modo racional las normas éticas de la existencia humana. En efecto, el pensamiento metafísico cree poder $d e d u$ cir las reglas de la vida buena de su descripción teórica de las estructuras esenciales del mundo. La "conciencia absoluta" del "orden absoluto" plantea al hombre una "exigencia absoluta", la exigencia de llevar una vida auténtica o verdadera, esto es, de ajustar su régimen de vida [lebensführung] a las leyes del ser (Horkheimer, 1933/1968). "Conservar el propio ser, o convertirse en aquello que uno es, rige entonces como máxima ética" (p. 39).

Algo similar sucede para Butler con la metafísica de género. El conocimiento absoluto de la ontología de género del que se jacta el common sense occidental tiene también consecuencias normativas: la heterosexualidad obligatoria aparece como una consecuencia obvia 
del conocimiento de la estructura esencial de la realidad sexual. De esta manera, la prescripción pasa como mera descripción; el carácter arbitrario y coercitivo del régimen normativo heterosexista se oculta detrás de la inocencia aséptica de una supuesta intelección absoluta de la constitución del ser. En otras palabras: saber que existen solo dos géneros sustanciales plantea naturalmente la exigencia inescapable de adecuar la propia vida a esta verdad última. No se puede ir en contra de la estructura de lo real, y, por tanto, los actos de género de los individuos deben limitarse a expresar el núcleo sustancial de la identidad sexual.

\section{El modelo performativo-teatral.}

Podría decirse que la deconstrucción butleriana del régimen heterosexista occidental trabaja simultáneamente en dos planos: uno macrosociológico -o estructural- $\mathrm{y}$ otro microsociológico $-\mathrm{O}$ fenomenológico-. Este modo dual de operar se apoya en una concepción dialéctica o sintética de lo social análoga a la de autores como Pierre Bourdieu (1980/2007). Desde esta óptica, el análisis crítico de un fenómeno social como la identidad de género debe dar cuenta no solo de sus condiciones objetivas de aparición -esto es, de la estructura social-, sino también de los factores subjetivos que actúan en su producción y reproducción -la acción social-. En este sentido, Butler parece seguir la vieja máxima marxiana: "los hombres hacen su propia historia, pero no la hacen a su libre arbitrio [...], sino bajo aquellas circunstancias con que se encuentran directamente, que existen y transmiten el pasado" (Marx, 1852/1968, p. 13).

Puede señalarse que sin seres humanos cuyos varios actos producen y mantienen condiciones opresivas, esas condiciones sucumbirían, pero debe observarse que la relación entre actos y condiciones no es unilateral ni inmediata. Hay contextos sociales y convenciones dentro de las cuales ciertos actos no solo se vuelven posibles sino también concebibles como actos (Butler, 1988, p. 525).
En un nivel macrosociológico, Butler coincide con Foucault en que el sistema de heterosexualidad obligatoria, entendido como un dispositivo disciplinario que cuadricula y regula el espacio social en toda su extensión, ha sido construido e impuesto estructuralmente en la modernidad occidental persiguiendo el objetivo de garantizar la reproducción de la especie. "Como Foucault y otros señalaron, la asociación de un sexo natural con un género discreto y con una 'atracción' ostensiblemente natural hacia el sexo/género opuesto es una conjunción no natural de constructos culturales al servicio de intereses reproductivos" (Butler, 1988, p. 524). El objetivo de la crítica estructural, consiste entonces en "centrar -y descentrar- estas instituciones definitorias: el falologocentrismo y la heterosexualidad obligatoria" (Butler, 1990/2007, p. 37). Este tipo de análisis crítico intenta desnaturalizar la heteronormatividad a través de un estudio genealógico orientado a visibilizar los intereses políticos que operan en la construcción e instauración de las categorías dominantes de identidad sexual (Butler, 1990/2007).

Ahora bien, sin dejar de reconocer la importancia fundamental de la crítica estructural al régimen heterosexualista, Butler indica que la misma comete el error de desvalorizar el rol de la acción subjetiva cotidiana en la construcción de la realidad de género. De modo similar a autores como Garfinkel (1967), Butler (1988) considera que la perspectiva estructural rebaja al sujeto al estatus de un cultural dope, en tanto lo concibe como una mera tabula rasa en la que se inscriben mandatos estructurales. Por esta razón, cree que la desestabilización teórica del régimen heterosexual occidental solo puede ser completa si se tiene en cuenta también "el modo mundano en el cual estos constructos [los referidos al género] son producidos, reproducidos y mantenidos dentro del terreno de los cuerpos" (Butler, 1988, p. 526). En otras palabras: la crítica macrosociológica o estructural debe ir de la mano con una crítica microsociológica o fenomenológica. 
En su análisis microsociológico de la construcción del género, Butler retoma de modo heterodoxo e idiosincrático algunos elementos de la tradición fenomenológica fundada por Edmund Husserl para releer a Simone de Beauvoir. Para Butler (1988), la fenomenología "busca explicar el modo mundano en que los agentes sociales constituyen la realidad social a través del lenguaje, los gestos y todo tipo de signo simbólico social" (p. 526). Desde la perspectiva butleriana, el análisis fenomenológico permite des-reificar el mundo social y captarlo in status nascendi, esto es, produciéndose y reproduciéndose constantemente en los actos constituyentes de la experiencia subjetiva cotidiana. Ahora bien, distanciándose de la sustancialización del sujeto propia de la fenomenología husserliana (c.f. Husserl, 1913/2009), Butler coincide con Nietzsche en que "no hay ningún 'ser' detrás del hacer, del actuar, del devenir; el agente ha sido añadido ficticiamente al hacer, el hacer es todo" (Nietzsche citado por Butler, 1990/2007, p. 85).

Así, la subjetividad no es un locus sustantivo del que brotan actos, sino más bien un producto contingente de estos últimos. Es decir, el agente social aparece "como un objeto antes que como el sujeto de los actos constitutivos" (p. 85.). De acuerdo con Butler, esta desustancialización del sujeto permite romper con la ya mencionada concepción expresiva de la identidad de género hegemónica en Occidente. Si se postula que no existe un sujeto sustantivo pre-dado del que emanan los actos constitutivos de la experiencia, también puede señalarse que no hay una identidad de género sustancial ligada esencialmente a ese sujeto, identidad que los actos de género se limitarían a expresar.

Siguiendo estos lineamientos fenomenológicos heterodoxos, Butler (1988) relee la clásica afirmación de Beauvoir: "una no nace, sino que se convierte en mujer" (p. 519). La teórica norteamericana toma el clásico dictum de Beauvoir como base para formular su concepción performativa del género. Aseverar que la identidad de género es performativa implica decir que la misma solo existe en y a través de un conjunto de actos de género. En palabras de Butler: "la realidad de género es performativa, lo cual significa, muy simplemente, que solo es real en la medida en que es performada" (p. 528). "Los variados actos de género crean la idea de género, y sin esos actos, no habría género alguno" (p. 522).

Para comprender cabalmente la concepción performativa butleriana de la identidad de género, es preciso dar cuenta con más precisión del carácter de estos actos constitutivos. Según Butler (1988) los actos de género son eminentemente corporales: se trata de gestos, movimientos, posturas, comportamientos, etc. En esta línea, puede aseverarse que Butler se distancia del mentalismo de la fenomenología de Husserl -para quien los actos constitutivos son vivencias intencionales de la conciencia pura (c.f. Husserl, 1913/2009)-, acercándose a posturas fenomenológicas que ponen el foco en la experiencia subjetiva de la corporalidad o el embodiment (c.f. Merleau-Ponty, 1945/1985).

Por otro lado, desde la posición butleriana, la performatividad de género no debe entenderse como un acto único y puntual, sino más bien como una serie de actos repetidos que se sostienen en el tiempo (Butler, 1990/2007). La repetición sostenida de ciertos actos corpóreos tiene como efecto la "estilización del cuerpo" (Butler, 1988, p. 519; 1990/2007, p. 17), es decir, la impresión en la carne de un estilo definido. En otras palabras: al ser reiterados ritual y sostenidamente, los gestos, comportamientos y posturas se sedimentan en la corporalidad dando origen a una suerte de habitus naturalizado. Es de esta manera como se constituye la "apariencia de sustancia" (Butler, 1990/2007, p. 274) de un gendered body, esto es, la ilusión de un cuerpo naturalmente "masculino" o "femenino".

El cuerpo deviene su género a través de una serie de actos que son renovados, revisados y consolidados a través del tiempo [...] debe intentarse reconcebir el gendered body como el 
legado de actos sedimentados antes que como una estructura predeterminada o forcluida, una esencia o hecho, ya sea natural, cultural o lingüística (Butler, 1988, p. 523).

De acuerdo con Butler (1990/2007), tanto la audiencia social como el actor mismo caen en las trampas de este espejismo de sustancia y terminan creyendo en el carácter natural y necesario de la realidad de género. "La apariencia de sustancia es exactamente eso, una identidad construida, una realización performativa en la que el público social mundano, incluidos los mismos actores, llega a creer y actuar en el modo de la creencia" (p. 274).

Butler (1988) considera además, y aquí reside uno de los aspectos vitales de su propuesta teórica temprana, que estos actos de género "guardan similitudes con los actos performativos dentro del contexto teatral" (p. 521). La autora estadounidense piensa que, tal como toda forma de embodiment, la identidad de género posee una estructura dramática. "Hacer, dramatizar, reproducir, estas parecen ser algunas de las estructuras elementales del embodiment" (p. 521.). Desde esta óptica, "uno no es simplemente un cuerpo [...] sino que hace su cuerpo" (p. 251). Este hacer el propio cuerpo, sin embargo, no es puramente libre; no brota de la voluntad y la creatividad del sujeto individual. Antes bien, reproduce un guion sociocultural que estipula los roles o papeles a ser performados, entendidos estos como estilos corporales predefinidos. De lo expuesto más arriba se sigue que en el guion de género vigente en Occidente -la heteronormatividad-, solo hay dos papeles o estilos corporales posibles: "hombre" y "mujer".

El acto que uno hace, el acto que uno performa, es un acto que ha estado en marcha antes de que uno haya llegado a escena. Por tanto, el género es un acto que ya ha sido ensayado, así como el guion sobrevive al actor particular que hace uso de él (p. 526).

Ahora bien, sostener que los papeles de género están prefijados por un guion social no implica, para Butler (1988), concebir el actor individual como un mero autómata que se limita a reproducir maquinalmente un patrón cultural. Si así fuera, la autora estaría cayendo en el mismo error reduccionista que le imputa a la perspectiva estructuralista.

[El] género no es una decisión radical o un proyecto que refleja una decisión meramente individual, pero tampoco es impuesto o inscrito sobre el individuo, como algunos desplazamientos posestructuralistas del sujeto señalarían. El cuerpo no es pasivamente inscrito con códigos culturales como si fuera un recipiente sin vida $[\ldots]$ (p. 256).

La crítica al objetivismo unilateral tiene en Butler una importancia no solo teórico-social sino también política. Por un lado, tal como se indicó, Butler considera que para ser exhaustivo, el análisis del fenómeno de la identidad de género debe tomar en cuenta tanto sus determinantes objetivos como los modos cotidianomundanos en los que se produce y reproduce. Pero por otro, siguiendo a Sara Salih (2007), debe señalarse que la agencia individual es central para Butler en la medida que "significa las oportunidades de subvertir la ley contra sí misma en pos de fines políticos radicales" (p. 55). En otros términos: el concepto de agencia alberga para Butler posibilidades de subvertir la heteronormatividad mediante modos diferentes de actuar y repetir el género. Estas posibilidades subversivas de la performatividad se ven totalmente ocluidas en posiciones estructuralistas y posestructuralistas que diluyen por completo el rol que desempeña la subjetividad en la constitución de la realidad social.

Butler (1988) apuntala estas ideas recurriendo una vez más a la metáfora teatral: para ser tal, una obra de teatro no solo precisa de un guion sino también de actores que le den vida y actualicen sus potencialidades. De hecho, un mismo texto puede ser performado de las más diversas maneras por diferentes intérpretes. De modo análogo, la realidad de género solo puede emerger a partir de la acción 
conjunta de estos dos momentos inseparables: la heteronormatividad -guion- $y$ los actos de género -actuación-.

Los actores están siempre ya en el escenario, dentro de los términos de la performance. Así como un guion puede ser representado de varios modos, y así como la obra requiere tanto del texto como de la interpretación, así también el cuerpo con género actúa su parte en un espacio cultural restringido corporalmente y representa interpretaciones dentro de los confines de directivas ya existentes (p. 526).

Otro rasgo central que los actos de género comparten con los performativo-teatrales es su carácter eminentemente público y colectivo (Butler, 1990/2007, p. 273). La performance teatral jamás es un acontecimiento meramente individual. A menos de que se trate de una pieza unipersonal, el protagonista está por lo general acompañado por otros actores en el escenario y, a su vez, la obra es presenciada por una audiencia. De manera similar, lejos de ser acontecimientos privados, los actos constitutivos de género se performan con otros y en frente de otros. Desde la perspectiva butleriana, en tanto fenómenos colectivos y públicos, los actos de género tienen un cariz ritual, casi litúrgico. En ellos, la coordinación temporal intersubjetiva tiene una importancia crucial. "Aunque haya cuerpos individuales que desempeñan estas significaciones al estilizarse en modos de género, esta 'acción' es pública. Estas acciones tienen dimensiones temporales y colectivas, y su carácter público tiene consecuencias" (p. 273).

Desde el punto de vista butleriano, un actor social cumple con el guion del drama de género cuando intenta personificar con relativo éxito el papel de género que le fue asignado en su nacimiento. Se trata de un intento de personificación, y no de una personificación lograda, porque los ideales morfológicos de género -la masculinidad y la feminidad- son, en última instancia, "sitios ontológicos fundamentalmente inhabitables" (Butler, 1990/2007, p. 284), esto es, "normas [...] fantasmáticas, imposibles de personificar" (p. 274). En este sentido, Butler puede afirmar que la performance de género es una imitación o una parodia siempre fracasada de originales de género imposibles de ser encarnados, solo existentes en un plano ideal (p. 269).

Los actores sociales, en efecto, tratan de acercarse a estos ideales mediante la repetición paródica sostenida de actos de género, sin conseguir jamás adecuarse completamente a ellos. Esto es así incluso en aquellos casos en los que las "esencias" masculina y femenina parecen haberse hecho carne en individuos particulares -por ejemplo, en las figuras del "héroe de guerra" y la "madre afectuosa", respectivamente-.

A la luz de lo precedente puede comprenderse con más facilidad el rol fundamental que ejerce el análisis del travestismo en la argumentación butleriana. Sustentada en el estudio de la antropóloga Esther Newton, Mother camp. Female impersonators in America, Butler asegura que la imitación hiperbólica y amplificada que las drag queens realizan del ideal morfológico femenino pone al descubierto el carácter imitativo de toda performance de género. Tanto la "travesti" como la "mujer biológica" intentan acercarse al ideal de la feminidad mediante la performance sostenida de actos de género. “¿Es el travestismo la imitación del género o bien resalta los gestos significativos a través de los cuales se determina el género en sí?" (Butler, 1990/2007, p. 37). "Al imitar al género, la travestida manifiesta de forma explícita la estructura imitativa del género en sí, así como su contingencia" (p. 269).

Ahora bien, a pesar de los isomorfismos, los actos de género difieren de los teatrales en un punto central. Dándole un giro a su argumentación que recuerda a Émile Durkheim (1985/2001) de Las reglas del método sociológico, Butler (1988) anota que "las performances de género en contextos no-teatrales están 
gobernadas por convenciones sociales punitivas y regulativas más claras" (p. 527). Es decir, los actos de género son vigilados y regulados por un severo aparato coercitivo que castiga a quienes performan su género de manera incorrecta. Aquellos que no cumplen con el papel que les ha sido asignado por la heteronormatividad sufren una sanción social que puede ir desde el desprecio y el ostracismo hasta la abierta violencia física. Basta pensar en las rigurosas consecuencias punitivas que deben enfrentar en Occidente los terceros excluidos en materia sexual por no seguir a rajatabla los férreos mandatos de la matriz heterosexualista. Para Butler (1988; 1990/2007) la performance de género es, en última instancia, una estrategia de supervivencia cultural. Performar el género correctamente, es un ardid que les garantiza a los individuos el reconocimiento de los prójimos y les permite eludir severos castigos psíquicos y físicos.

Por consiguiente, como una táctica de supervivencia dentro de sistemas obligatorios, el género es una actuación con consecuencias decididamente punitivas. Los géneros diferenciados son una parte de lo que "humaniza" a los individuos dentro de la cultura actual; en realidad, sancionamos constantemente a quienes no representan bien su género (Butler, 1990/2007, p. 272).

\section{Beatriz Preciado: la era farmaco pornográfica, el posmoneyismo y el modelo biodrag}

\section{La era farmacopornográfica.}

En los escritos de la autora española Beatriz Preciado, puede rastrearse un modelo teórico alternativo de la construcción de la identidad de género que invita a pensar en los límites de la concepción performativo-teatral butleriana. Este novedoso modelo teórico, que puede denominarse modelo biodrag, se sustenta en un ambicioso diagnóstico macrosociológico acerca de la especificidad del capitalismo actual, diagnóstico que difícilmente pueda encontrarse en los escritos de Butler. En efecto, si se quiere comprender el modo en que Preciado concibe la construcción de la identidad sexual en el plano de la cotidianidad contemporánea, es preciso antes bosquejar los rasgos fundamentales de su penetrante análisis de las sociedades capitalistas de hoy en día.

De acuerdo con Preciado (2008) en la actualidad nos encontramos en una flamante etapa del capitalismo: la era farmacopornográfica. Esta nueva fase capitalista, que comienza a desarrollarse incipientemente durante la posguerra y se consolida de forma definitiva en los años setenta debido a la crisis del petróleo, se caracteriza por colocar la gestión biotecnológica de la sexualidad en el centro de la actividad económica. Para la filósofa española, el negocio del nuevo milenio es "la gestión política y técnica del cuerpo, del sexo y la sexualidad" (p. 26), gestión que se realiza por medio de mecanismos "biomolecular[es] (fármaco) y semiótico-técnico[s] (porno) [...] de los que la píldora y Playboy son [ejemplos] paradigmáticos" ( $\mathrm{p}$. 30). En este sentido, a diferencia del capitalismo fordista, el farmacopornocapitalismo no produce objetos concretos sino "ideas móviles, órganos vivos, símbolos, deseos, reacciones químicas, estados del alma" (p. 45).

Para dar cuenta del funcionamiento peculiar de esta nueva fase del capitalismo, Preciado acuña el concepto de "fuerza orgásmica" o potentia gaudendi. "Se trata de la potencia (actual o virtual) de excitación (total) de un cuerpo" (p. 38). Esta novedosa noción desempeña en el análisis de Preciado un rol análogo al que poseía el concepto de "fuerza de trabajo" en la teorización marxiana del capitalismo clásico. En el capitalismo decimonónico teorizado por Marx, la ganancia provenía de la extracción de plusvalía de la fuerza de trabajo fabril; en el farmacopornocapitalismo de Preciado, en cambio, el beneficio económico surge de la explotación de la fuerza orgásmica a través de dispositivos biotecnológicos de control de la subjetividad sexual. "El sexo, los órganos sexuales, el pensamiento, la atracción, se desplazan al centro de 
la gestión tecnopolítica en la medida en la que está en juego la posibilidad de sacarle provecho a la fuerza orgásmica" (p. 40).

El nombre que Preciado elige para designar este nuevo tipo de capitalismo "caliente, psicotrópico y punk" (p. 30) refleja el entrelazamiento intrínseco que existe entre sus dos industrias fundamentales: la farmacéutica y la pornográfica. "La industria farmacéutica y la industria audiovisual del sexo son los dos pilares sobre los que se apoya el capitalismo contemporáneo, los dos tentáculos de un gigantesco y viscoso circuito integrado" (p. 45). De acuerdo con Preciado, el vínculo entre ambas industrias se expresa en el programa de acción del farmacopornocapitalismo: "controlar la sexualidad de los cuerpos codificados como mujeres y hacer que se corran los cuerpos codificados como hombres" (p. 45).

El objetivo farmacéutico -orientado principalmente hacia las 'mujeres'- y el pornográfico -dirigido sobre todo a los 'hombres'- son complementarios y coadyuvantes. "No hay pornografia" - para 'hombres'- "sin una vigilancia y un control farmacopolítico paralelo" (p. 44) -de la sexualidad de las 'mujeres'-. Para decirlo de otra manera: la píldora anticonceptiva y Playboy, emblemas del control farmacéutico y pornográfico de la subjetividad sexual que emerge en los años cincuenta, no pueden comprenderse el uno sin el otro. El "macho" viril deseoso de descargar su potencia orgásmica a toda costa no es más que el complemento perfecto de la "mujer" sumisa consumidora de la píldora que aparece desnuda en Playboy. Además, para Preciado (2008), "la transformación progresiva de la cooperación sexual en principal fuerza productiva no podría darse sin el control técnico de la reproducción" (p. 44). En otros términos: no es posible liberar las potencialidades de la fuerza masturbatoria "masculina" sin el desarrollo de mecanismos anticonceptivos "femeninos" como la píldora. Pareciera, entonces, que gracias al éxito del programa farmacopornográfico de la segunda mitad del siglo XX, la matriz heterosexualista occidental se afianza $\mathrm{y}$ robustece. Radicalizando este argumento, para Preciado (2008) "la masculinidad y la feminidad son inventos de la Segunda Guerra Mundial que conocerán su plena expansión comercial durante la Guerra Fría como la comida enlatada [y] el ordenador [...]" (p. 81).

\section{El posmoneyismo.}

De acuerdo con Preciado (2008; 2009) la era farmacopornográfica da pie al surgimiento de un nuevo régimen de la sexualidad, el denominado posmoneyismo, que viene a reemplazar al régimen disciplinario decimonónico teorizado por Michel Foucault. Como se detallará a continuación, el posmoneyismo se caracteriza por gobernar la subjetividad sexual mediante dispositivos biotecnológicos de carácter microprostético inexistentes en el siglo XIX y comienzos del XX.

Foucault soslaya un conjunto de transformaciones que se suceden a partir de la Segunda Guerra Mundial y que, en mi opinión, exigen una tercera episteme, ni soberana ni disciplinaria, ni premoderna ni moderna, que tenga en cuenta el impacto de las nuevas tecnologías del cuerpo, una episteme que llamo posmoneyista, haciendo referencia a la figura del Dr. John Money (Preciado, 2009, p. 20).

Para la teórica española, el índice de la eclosión de esta nueva episteme sexual es la aparición de la categoría de "género" (gender). Lejos de tratarse de un invento del feminismo de la década del sesenta, esta categoría es un producto del discurso médico de fines de los años cuarenta. A principios de la Guerra Fría, avizorando el negocio farmacopornográfico del nuevo milenio, Estados Unidos comienza a invertir fuertes sumas de dinero en investigación científica sobre sexo y sexualidad (Preciado, 2009, p. 21). En este contexto, el psiquiatra John Money, especializado en el estudio de bebés intersexuales, desarrolla el concepto de gender. Money define el género como la "pertenencia de un individuo a un grupo cultural reconocido como masculino o femenino" (Preciado, 2008, 
p. 27), distinguiéndolo de la categoría biológica de "sexo", hegemónica en el régimen sexual disciplinario del siglo XIX.

En contraste con la rigideze inmutabilidad del sex disciplinario, el gender posmoneyista tiene un carácter plástico y flexible. Para Money, en efecto, el género de cualquier niño puede ser modificado antes de los 18 meses de edad mediante procedimientos quirúrgicos y tratamientos hormonales (Preciado, 2009, p. 21). "Si en el sistema disciplinario decimonónico, el sexo era natural, definitivo, intransferible y trascendental; el género aparece ahora como sintético, maleable, variable, susceptible de ser transferido, imitado, producido y reproducido" (Preciado, 2008, p. 82). Preciado considera que la introducción de la categoría de género abre "la posibilidad de usar la tecnología para modificar el cuerpo según un ideal regulador preexistente de lo que un cuerpo humano (femenino o masculino) debe ser" (Preciado, 2009, p. 22). Por tanto, puede afirmarse que el concepto de gender constituye la condición de posibilidad de la aparición de un conjunto de novedosas técnicas de normalización y transformación de la subjetividad sexual -fundamentalmente endocrinológicas y quirúrgicas- que le darán al posmoneyismo su complexión particular.

Según Preciado $(2008 ; 2009)$ existe una distancia abismal entre las técnicas de normalización de los cuerpos sexuales que imperaban en el régimen disciplinario de la sexualidad y aquellas que rigen hoy en día, en el régimen posmoneyista. En el régimen disciplinario decimonónico, las técnicas de control eran inmensas, rígidas y externas a la subjetividad. El modelo paradigmático de dispositivo disciplinario era la arquitectura de la prisión, a cuya estructura extraña, el cuerpo debía adaptarse ortopédicamente. Por el contrario, las técnicas normalizadoras posmoneyistas son pequeñas, flexibles y blandas (Preciado, 2008; 2009). Las mismas son asimiladas e internalizadas por los cuerpos, inscribiéndose en "la estructura misma del ser vivo" (Preciado, 2008, p. 87).
Aquí el modelo paradigmático lo constituyen los dispositivos endocrinológicos en general y la píldora anticonceptiva en particular. El sujeto farmacopornográfico deja de habitar en dispositivos disciplinarios externos como la prisión, para pasar a ser habitado por técnicas internas de control de la sexualidad como la píldora. El panóptico se vuelve comestible; la ortopedia disciplinaria deja su lugar a la microprostética posmoneyista (p. 135).

[...] asistimos a la progresiva infiltración de técnicas de control social del sistema decimonónico disciplinario dentro del cuerpo individual. Ya no se trata ni de castigar las infracciones sexuales de los individuos ni de vigilar y corregir sus desviaciones a través de un código de leyes externas, sino de modificar sus cuerpos en tanto que plataforma viva de órganos, flujos, neurotransmisores y posibilidades de conexión y agenciamiento, haciendo de estos al mismo tiempo el instrumento, el soporte y el efecto de un programa político. Cierto, estamos ante una forma de control social, pero de "control pop", por oposición al control frío y disciplinario que Foucault había caracterizado con el modelo de la prisión de Jeremy y Samuel Bentham, el panóptico (p. 134).

Veamos ahora el modo en que la píldora anticonceptiva, el procedimiento posmoneyista de control de la sexualidad par excellence, opera en la construcción de la feminidad. Según la filósofa en cita, lejos de ser un mero método de control de la natalidad, la pill es una poderosa técnica microprostética de producción del género femenino (Preciado, 2008; 2009). El propósito principal de la píldora no es impedir la concepción, sino feminizar los cuerpos de las consumidoras, es decir, volverlos acordes con el ideal morfológico "mujer" tal como es definido por las sociedades occidentales contemporáneas.

La pillno solo regulariza el ciclo menstrual adecuándolo a los ritmos de la "feminidad natural"; también posee una serie de efectos cosméticos feminizantes: mejora la calidad de la piel, impide el acné y el crecimiento de vello corporal y facial, produce un aumento del 
volumen de los pechos, etc. (Preciado, 2008, p. 141). Además, y esto es de suma importancia en la argumentación de Preciado, la píldora feminiza la complexión psíquica de las mujeres: estas adquieren un humor lánguido y depresivo, experimentan una disminución de la libido y se vuelven pasivas y sumisas. La pill produce "el alma del sujeto heterosexual mujer moderno", el "alma químicamente regulada de la putita heterosexual sujeta a los deseos sexuales del bio-macho de Occidente" (p. 137). "La cuestión es administrarme la dosis farmacopornográfica necesaria de estrógenos y progesterona para transformarme en una hembra sumisa, de grandes senos, humor depresivo pero estable, sexualidad pasiva o frigidez" (p. 141).

\section{Modelo biodrag vs. Modelo perfor- mativo-teatral.}

Siguiendo estos lineamientos, Preciado (2008) sostiene que por "definición, el cuerpo femenino nunca es completamente normal fuera de las técnicas que hacen de él un cuerpo social" (p. 147), es decir, fuera del consumo de preparados hormonales. En otras palabras: las biomujeres - esto es, las mujeres supuestamente "naturales"- son, en realidad, "artefactos industriales modernos, tecnoorganismos de laboratorio" (p. 147). Incluso luego de la menopausia, las mujeres siguen subordinándose a procedimientos microprostéticos hormonales que tienen como objetivo mantener la feminidad a pesar de la desaparición del ciclo menstrual.

[...] la tecno-mujer del siglo XXI se convierte en una potencial consumidora de hormonas sintéticas durante casi cincuenta años: a los cincuenta del tratamiento anticonceptivo vienen a sumarse hoy diez o quince años de tratamiento post-menopáusico (p. 137).

Apoyada en señalamientos de Donna Haraway, Preciado indica que en el farmacopornocapitalismo, debe hablarse de tecnocuerpo y no meramente de cuerpo. Efectivamente, hoy en día es imposible concebir un cuerpo "natural" o biológico puro que no esté sometido, de alguna forma, al control biotecnológico del farmacopornismo. El cuerpo posmoneyista es una "entidad tecnoviva multiconectada que incorpora tecnología. Ni organismo, ni máquina: tecnocuerpo" (Preciado, 2008, p. 39). Siguiendo esta línea de pensamiento, la autora realiza una afirmación análoga en referencia a la noción de género. En la actualidad, la noción de género debería dejar su lugar a la de tecnogénero. "Sería [...] más correcto en términos ontopolíticos, hablar de tecnogénero, si queremos dar cuenta del conjunto de técnicas fotográficas, biotecnológicas, quirúrgicas, farmacológicas, cinematográficas o cibernéticas que constituyen performativamente la materialidad de los cuerpos" (p. 86).

Se llega así al punto en que la posición de Preciado pone en crisis el modelo performativoteatral butleriano de la construcción cotidiana de la identidad de género. Es cierto que la pensadora española en ningún momento tiene la intención de llevar a cabo un análisis fenomenológico de la constitución cotidiana del género como el realizado por Butler. Sin embargo, de sus desarrollos teóricos puede deducirse un modelo teórico alternativo de la construcción del género que está capacitado para dar cuenta de aspectos de la cotidianidad contemporánea descuidados por la concepción performativa butleriana.

Como se mostró en el apartado anterior, para Butler la identidad de género es construida en el plano cotidiano mediante la repetición sostenida de actos corporales estilizados que intentan acercarse o imitar un ideal morfológico de género. Desde la posición butleriana, en efecto, una "mujer" se constituye como tal mediante la performance continua de gestos, comportamientos y movimientos que siguen las directivas del rol de género femenino, tal como es definido por el guión de la heteronormatividad. Sin dejar de reconocer los méritos de esta concepción, Preciado (2009) considera que la misma "tropieza cuando se trata de explicar la modificación de la estructura de la vida que opera en nuestra sociedades 
posmoneyistas", ya que "ignora las tecnologías de incorporación específicas que funcionan en las diferentes inscripciones performativas de la identidad" (p. 31).

Tal como se consignó unas líneas más arriba, de acuerdo con Preciado, en la era farmacopornográfica y posmoneyista, el cuerpo se torna tecnocuerpo, y el género, tecnogénero. Desde esta posición, una "mujer" solo puede constituirse como tal si se somete a una serie de técnicas microprostéticas. Según Preciado, entonces, la constitución cotidiana o mundana de la feminidad no consiste en la repetición de actos corpóreos estilizados, sino más bien en el consumo sostenido de preparados hormonales. En otras palabras: en la era farmacopornográfica, un sujeto se constituye mundanamente como "mujer" no mediante una performance cuasiteatral, sino a través de su sometimiento continuo a dispositivos biotecnológicos de control como la píldora anticonceptiva. En este nuevo modelo teórico de la construcción de género, la actuación cuasiteatral deja su lugar al consumo regulado de fármacos.

Como también se señaló, para Butler la mera repetición performativa conduce a una habituación de la corporalidad que da surgimiento a la ilusión de la "naturalidad" de género, ilusión en cuyas trampas cae tanto el actor como la audiencia. Desde la perspectiva de Preciado (2009), sin embargo, la sedimentación corporal no es suficiente para constituir el efecto de "naturalidad"; antes bien, esta solo puede lograrse mediante la modificación orgánica, somática, de los cuerpos generada por procedimientos hormonales o quirúrgicos. "El concepto de performance de género, y más aún el de identidad performativa, no permite tomar en cuenta los procesos biotecnológicos que hacen que determinadas performances 'pasen' por naturales y otras, en cambio, no" (p. 31).

A pesar de estas marcadas diferencias, existe una similitud estructural entre los modelos teóricos de Preciado y Butler ${ }^{3}$. En las argumen- taciones de ambas pensadoras, el análisis de los sujetos "desviados" o "anormales" -la travesti, la transexual, el hermafrodita, etc.- desempeña un papel cardinal en tanto permite sacar a la luz el modo obvio $-y$, por tanto, invisible- en que se construye el género "normal". Para Butler, al performar la feminidad de modo hiperbólico, la drag queen pone de manifiesto con claridad el carácter imitativo y performativo que siempre posee la identidad de género. Por su parte, en el esquema teórico de Preciado, la biodrag o la transexual mujer cumple un papel similar a la drag queen butleriana ${ }^{4}$. En la medida en que consume una multiplicidad de preparados hormonales y se somete a operaciones quirúrgicas para feminizar su cuerpo, la biodrag realiza de manera consciente, esclarecida e hiperbólica aquello que las biomujeres hacen inconsciente y oscuramente en la cotidianidad farmacopornista. Para Preciado (2009) "a partir de la década de 1950, la construcción de la feminidad es en todos los casos un proceso de travestismo somático o de biodrag" (p. 34). Ahora bien, mientras que la transexual sabe que está sirviéndose de estas técnicas, "la mujer biológica estadounidense típica se [las] traga de forma inconsciente [...] como si se tratara de complementos 'naturales' de su feminidad" (p. 33).

\section{Conclusiones}

Este trabajo se planteó como objetivo contrastar las perspectivas teóricas de Butler y Preciado acerca de la construcción del género. Con este fin, en el primer apartado se presentaron los lineamientos fundamentales de la crítica de Butler a la metafísica de género, para luego bosquejarse los rasgos de su concepción performativo-teatral. En el segundo se esbozó el análisis de Preciado del farmacopornocapitalismo y el posmoneyismo, y se expusieron los rasgos principales del modelo biodrag que se sigue de su diagnóstico macrosociológico.

Como pudo observarse, a pesar de la existencia de analogías argumentales, se constatan diferencias en los modelos teóricos de las 
autoras. Mientras que Butler coloca el eje en la performance cotidiana de actos corpóreos cuasiteatrales, Preciado focaliza su atención en la incorporación y el consumo de técnicas microprostéticas como síntoma del advenimiento de un nuevo régimen sexual: el posmoneyismo.

El excesivo énfasis de Butler en la performatividad teatral la hace desatender el rol primordial que tiene hoy en día, en pleno auge del posmoneyismo, los procesos biodrag en la construcción de las identidades sexuales. En contraste, Preciado sí reconoce la importancia de estos procesos, pero no realiza un análisis fenomenológico pormenorizado de las performances dramático-corpóreas; análisis que sí puede encontrarse en la obra de la escritora estadounidense.

La constatación de divergencias entre los dos modelos teóricos no implica que los mismos sean mutuamente excluyentes. Por el contrario, se cree que las posiciones de las dos filósofas son complementarias. En este sentido, Preciado (2009) está en lo cierto cuando afirma que el modelo biodrag no debe pensarse "como una ruptura con el marco de análisis butleriano, sino como un aporte a lo que la propia Butler llama, sin dejar demasiados detalles, una consideración escenográfica y topográfica de la construcción del sexo" (p. 32).

La construcción de la identidad de género en las sociedades contemporáneas es un fenómeno multidimensional que no puede ser aprehendido de un solo golpe. En este sentido, para hacerle justicia a su complejidad, resulta en suma útil aplicar conjuntamente modelos teoréticos divergentes como los de Butler y Preciado.

Las reflexiones planteadas en este escrito no solo constituyen un aporte al análisis teóricofilosófico de la construcción de la identidad sexual, sino que también pueden ser fructuosas para brindarles rigurosidad conceptual a las investigaciones empíricas sobre la temática que se desarrollan en diferentes disciplinas de las ciencias humanas.

\section{Notas}

1 Las citas de textos en inglés y alemán son traducciones propias.

2 En general, suelen diferenciarse dos etapas en la obra de Butler (Preciado, 2009, p. 28; Salih, 2007, p. 57). Una primera fase, en la que la autora promulga el modelo performativoteatral, y una segunda, en la cual "trata de redefinir la performance teatral en términos de performatividad lingüística (Austin releído por Derrida)" (Preciado, 2009, p.28). En este trabajo, se resaltará la primera Butler, que es la que le interesa a Preciado.

3 Este isomorfismo argumental obedece posiblemente a la influencia que ejerce Butler en Preciado.

4 A este respecto, en Preciado (2009) es paradigmático el caso Agnès.

\section{Referencias}

Bourdieu, P. (2007). El sentido práctico. Buenos Aires: Siglo XXI.

Butler, J. (1988). Performative Acts and Gender Constitution: An Essay in Phenomenology and Feminist Theory. Theatre Journal, 40(4), 519-531.

Butler, J. (2002). Cuerpos que importan: sobre los límites materiales y discursivos del 'sexo'. Buenos Aires: Paidós.

Butler, J. (2007). El género en disputa. El feminismo y la subversión de la identidad. Buenos Aires: Paidós.

De Lauretis, T. (1987). Technologies of Gender: Essays on Theory, Film, and Fiction. Bloomington: Indiana University Press. 
Durkheim, É. (2001). Las reglas del método sociológico. Madrid: Akal.

Femenías, M. L. (diciembre, 2003). Aproximación al pensamiento de Judith Butler. Trabajo presentado en Conferencia. Gijón. Recuperado de http://www.comadresfeministas.com/publicaciones/enlaweb/femenias.pdf

Fonseca-Hernández, C., \& Quintero-Soto, M. L. (2009). La teoría Queer: la de-construcción de las sexualidades periféricas. Sociológica, 24(69), 43-60.

Garfinkel,H.(1967).StudiesinEthnomethodology. Nueva Jersey: Prentnice-Hall.

Horkheimer, M. (Ed.) (1968). Materialismus und Metaphysik. En Kritische Theorie, Band I (pp. 31-67). Frankfurt am Main: Fischer.

Husserl, E. (2009[1913]). Ideen zu einer reinen Phänomenologieundphänomenologischen Philosophie. Erstes Buch. Allgemeine Einführung in die reine Phänomenologie. Hamburgo: Felix Meiner.

Leciñana-Blanchard, M. (2006). Crisis del sujeto desde el feminismo filosófico y sus perspectivas en América Latina. En Femenías, L. M. (Ed.), Feminismos de París a La Plata (pp. 127-145). Buenos Aires: Catálogos.

Leibniz, G. W. (2004). Tratados fundamentales. Discurso de metafísica. Buenos Aires: Losada.
Marx, K. (1968). El 18 Brumario de Luis Bonaparte. Madrid: Akal.

Merleau-Ponty,M.(1985[1945]).Fenomenología de la percepción. Barcelona: Planeta-De Agostini.

Osborne, R. (1993). La construcción sexual de la realidad. Un debate en la sociología contemporánea de la mujer. Madrid: Cátedra.

Preciado, B. (2008). Testo yonqui. Madrid: Espasa Calpe.

Preciado, B. (2009). La invención del género, o el tecnocordero que devora a los lobos. En Conversaciones Feministas, Biopolítica (pp. 15-38). Buenos Aires: Ají de pollo.

Preciado, B. (2010). Preciado en el Claustro de Sor Juana [Video]. México. Recuperado de http://www.youtube.com/watch?v=z_NmI-DcNo

Preciado, B. (2012). "Queer": Historia de una palabra. paroledequeer Recuperado de http://paroledequeer.blogspot.com. co/2012/04/queer-historia-de-una-palabra-por.html

Salih, S. (2007). On Judith Butler and Performativity. En K. Lovaas \& M. Jenkins (Eds.), Sexualities \& Communication in Everyday Life: A Reader (pp. 55-68). Londres: Sage.

Sedwick, E. K. (1990). Epistemology of the Closet. Londres: University of California Press. 